\title{
The variation of the lower anterior facial height and its component parameters among the three over bite relationships (Cephalometric study)
}

Saba H Al-Zubaidi BDS, MSc (Assist Lect)

Hussain AA Obaidi BDS, MD (Assist Prof)

\author{
Dept of Pedod, Orthod and Prev Dent \\ College of Dentistry, University of Mosul
}

\begin{abstract}
Aims: To evaluate the genders and over bite subjects group variation for the lower anterior facial height (LAFH) and its component parameters in Iraqi population in Mosul City. Materials and Methods: The study was performed by using measurements on pretreatment cephalometric radiographs of 79 patients, 27 with normal over bite and 26 for each open and deep over bite. The age ranged from 12-16 years with Class I dentoskeletal relationship. Results: The normal over bite group was significantly larger maxillary anterior alveolar ratio and the mandibular anterior and basal height in male when compared with female. Deep bite group appeared significantly larger mandibular anterior alveolar depth in males than in females. The open bite group showed significantly larger interincisal angle in females than in males. Multiple range variation analysis of the lower facial height and its component parameters disclosed no significant differences in these parameters among the over bite groups except that the open bite group was significantly larger mean value in the LAFH and significantly lower mean value in the interincisal angle when compared with normal and deep bite groups. Conclusion: The significant gender variation of the LAFH and its components of the normal over bite group were appeared in maxillary anterior alveolar depth, ratio and mandibular anterior alveolar height; whereas in deep bite group appeared in mandibular anterior alveolar depth, and in open bite group demonstrated in the interincisal angle.

Key Words: Facial height, alveolar height, alveolar depth, basal-alveolar ratio.
\end{abstract}

Al-Zubaidi SA, Obaidi HA. The variation of the lower anterior facial height and its component parameters among the three over bite relationships (Cephalometric study). Al-Rafidain Dent J. 2006; 6(2): 106-113.

Received: $28 / 9 / 2005$

Sent to Referees: 5/10/2005

Accepted for Publication: 8/12/2005

\section{INTRODUCTION}

The lower anterior facial height (LA$\mathrm{FH})$ is defined as the vertical distance between the anterior nasal spine and the menton points. ${ }^{(1,2)}$ Obviously this distance is potentially affected by the more increment or reduction through the compensatory growth pattern of the basoalveolar bone, and the dental eruption. The divergent growth pattern of the facial bones permits the vertical growth of the dentoalveolar components. ${ }^{(3)}$

The anterior vertical disturbances can be described as anterior open bite or deep bite. Open bite could be due to normal eruption of posterior teeth associated with incomplete eruption of the anterior teeth, excessive eruption of posterior teeth accompanied with normal eruption of anterior tee- th (the mandible rotates downward and backward). This facial pattern is called long face. The reverse is true in deep bite; in this circumstance, the incisor teeth erupt normally but the insufficient eruption of the posterior teeth associated with upward forward rotation of the mandible. This facial pattern is called short face. Correcting an accompanying deep bite or open bite may require an alteration in the vertical position of the posterior teeth, so the mandible can rotate to more normal inclination. ${ }^{(4)}$ The orthodontic movement of teeth takes place in the alveolar bone of both maxilla and mandible and fails to involve the basal bone. ${ }^{(5)}$ Cephalometric analysis is required for evaluation of patient with vertical problems for a goal of accurately corrections of skeletal and dental relations. ${ }^{(4)}$ Adams 
and Kerr ${ }^{(6)}$ found significant negative correlation between the lower face height and the over bite. This finding was supported with that of Dung and Smith; ${ }^{(7)}$ while Fle$\operatorname{ming}^{(8)}$ reported that there was a significant positive correlation between the over bite and dentoalveolar height.

It was reported that there were a significant difference between patients with normal and deep bites in the dentoalveolar region of maxilla. ${ }^{(9,10)}$ Deep bite subjects were associated with smaller lower facial height and a more widened shape of the symphysis. ${ }^{(11)}$

The open bite subjects were showed significantly smaller maxillary and mandibular alveolar and basal cross-section area compared with normal over bite or the deep bite. ${ }^{(11)}$

The vertical variation of the over bite probably coincides with a relative hyperdevelopment or hypodevelopment of the symphysis. ${ }^{(12)}$

A certain relationship may exist between the structure of the anterior part of the maxilla and the mandible and the LAFH for the anterior over bite relationships in Iraqi subjects.

This study was planned to evaluate the variation of the LAFH and its components among the three types of anterior overbite in Class I dentoskeletal relationships in Iraqi adolescents who live in Mosul City.

\section{MATERIALS AND METHODS}

The sample comprised of 79 lateral cephalemetric radiographs for each gender of age 12-16 years for the Iraqi patients live in Mosul City, who were not treated orthodontically. They were attended the Department of Pedodontics, Orthodontics and Preventive Dentistry, College of Dentistry, University of Mosul.

The criteria of the selected sample subjects were Class I molar and skeletal relationships (The ANB angle of the lateral cephalometric of the subject was zero to 2 degrees), normal bite $1-4 \mathrm{~mm}^{(13)}$ (13 males and 14 females), open bite less than $1 \mathrm{~mm}$ (15 males and 11 females) and deep bite more than $4 \mathrm{~mm}$ (13 for each gender).

The lateral cephalometric radiographs of the sample subjects were traced and de- fined the ANB angle according to Stien$\mathrm{er},{ }^{(14,15)}$ the LAFH (ANS-Me) as defined by Wylie $^{(1)}$ and Bjork, ${ }^{(16)}$ the interincisal (IIA) angle as defined by Downs ${ }^{(17,18)}$ and Stiener, ${ }^{(19)}$ the maxillary anterior alveolar and basal height (MxAABH), the mandibular anterior alveolar and basal height $(\mathrm{MdAABH})$, the maxillary anterior alveolar depth (MxAAD), the mandibular anterior alveolar depth (MdAAD), the ratio of the $\mathrm{MxAAD} / \mathrm{MxAABH}$ and the ratio of the MdAAD/MdAABH as defined by Reiolo et $a .^{(9)}$ (Figure 1). The LAFH and the component parameters of the lower anterior height were measured and recorded for the three types of over bites.

The results were analyzed and included the descriptive analysis: Mean values, standard deviation, standard error, maximum and minimum values; the Student's ttest at 0.05 significant level to reveal the gender variation of these parameters and applying the analysis of variance (ANOVA) and Duncan's Multiple Range Test analyses at 0.05 significant level to evaluate the variation of these parameters among the groups.

\section{RESULTS}

The descriptive and gender variation analyses of the LAFH and its component parameters for the three types of the overbite groups were presented in Tables (1), (2) and (3).

The open bite group showed higher mean value than the normal and deep bite groups in the following parameters: LA$\mathrm{FH}$, and MdAABH, meanwhile showed the lower mean value in the IIA angle, MxAABH, maxillary anterior alveolar ratio (MxAAR), MdAAD, mandibular anterior alveolar ratio (MdAAR) parameters for both genders and MxAAD in male.

The deep bite subject group revealed greater mean value than the normal over bite group in the IIA, MxAABH and MdAAD parameters for both genders and MdAAR parameter for males, whereas in (MxAAD), (MxAAR) and (MdAABH) parameters for females. The deep bite also appeared lower mean value than normal overbite group in the LAFH for both genders and MxAAD, MxAAR and MdAABH for males, whereas MdAAR for females. 


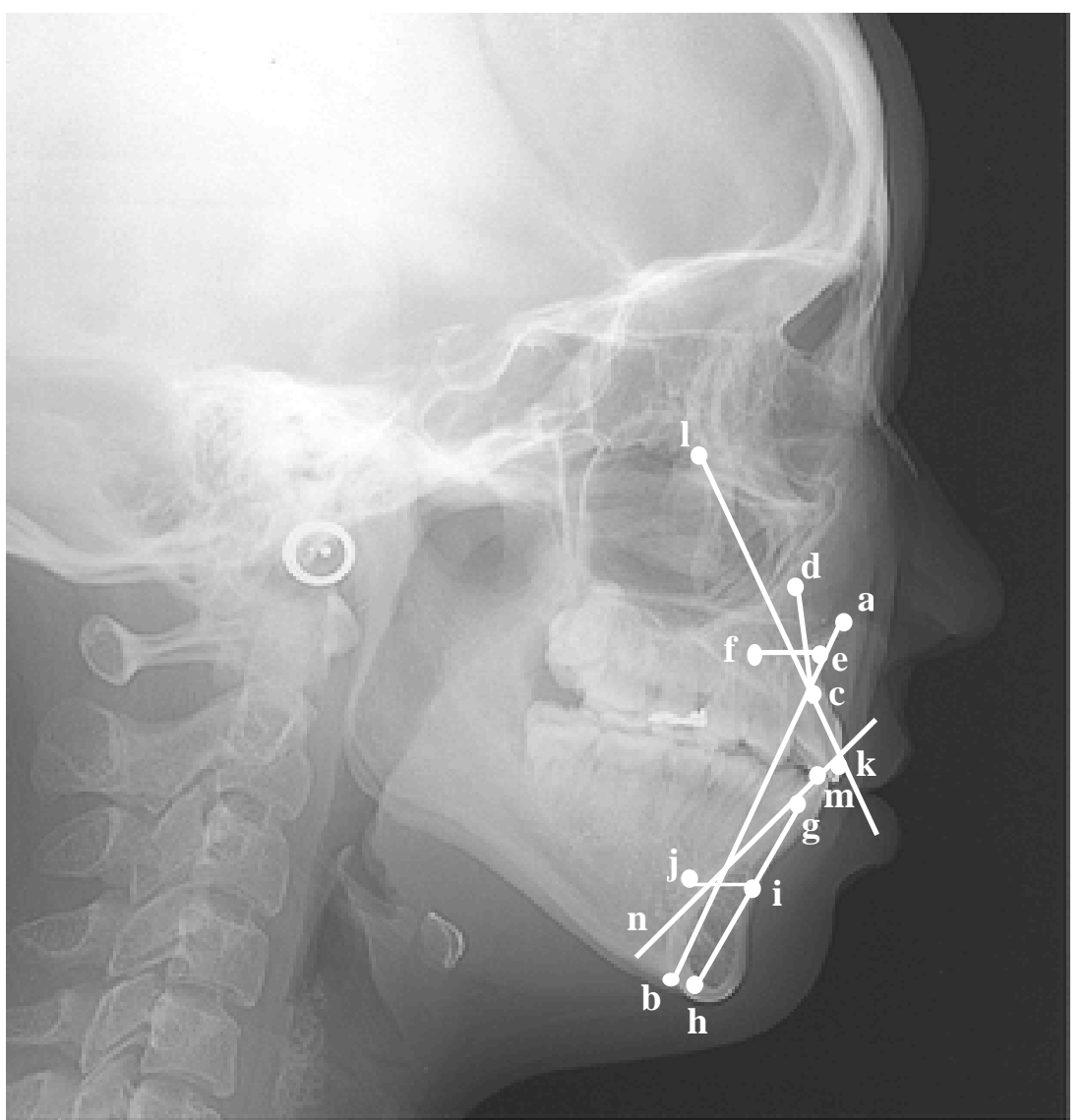

Figure (1): The lower facial height and its component parameters a-b: Lower facial height; c-d: Maxillary anterior alveolar basal height; e-f: Maxillary anterior alveolar depth; g-h: Mandibular anterior alveolar basal height; i-j: Mandibular anterior alveolar depth; kl-mn: Interincisal angle.

Table (1): Descriptive and gender's variation analyses of the anterior facial height and its component parameters in normal bite group

\begin{tabular}{|c|c|c|c|c|c|c|c|}
\hline Variables*** & Sex* & $\begin{array}{l}\text { Mean } \\
\text { Value }\end{array}$ & \pm SD & $\begin{array}{c}\text { Minimum } \\
\text { Value }\end{array}$ & $\begin{array}{c}\text { Maximum } \\
\text { Value }\end{array}$ & $\begin{array}{c}\text { t- } \\
\text { value }\end{array}$ & Sig.** \\
\hline Lower Anterior & $\mathbf{M}$ & 72.04 & 4.81 & 65 & 79.5 & \multirow{2}{*}{1.66} & \multirow{2}{*}{ NS } \\
\hline Facial Height & $\mathbf{F}$ & 69.18 & 4.15 & 62 & 74.5 & & \\
\hline \multirow{2}{*}{ Interincisal Angle } & $\mathbf{M}$ & 124.77 & 7.77 & 113 & 138.5 & \multirow{2}{*}{-0.20} & \multirow{2}{*}{ NS } \\
\hline & $\mathbf{F}$ & 125.50 & 10.10 & 110 & 147 & & \\
\hline Maxillary Anterior & $\mathbf{M}$ & 21.50 & 1.38 & 19 & 24 & \multirow{2}{*}{1.27} & \multirow{2}{*}{ NS } \\
\hline Alveolar and Basal Height & $\mathbf{F}$ & 20.68 & 1.92 & 18.5 & 24 & & \\
\hline Maxillary Anterior & $\mathbf{M}$ & 18.65 & 5.76 & 11 & 30 & \multirow{2}{*}{3.26} & \multirow{2}{*}{$\mathrm{S}$} \\
\hline Alveolar Depth & $\mathbf{F}$ & 13.00 & 2.90 & 9 & 19.5 & & \\
\hline Maxillary Anterior & $\mathbf{M}$ & 0.869 & 0.255 & 0.458 & 1.276 & \multirow{2}{*}{2.95} & \multirow{2}{*}{$\mathrm{S}$} \\
\hline Alveolar Ratio & $\mathbf{F}$ & 0.633 & 0.152 & 0.391 & 1.000 & & \\
\hline Mandibular Anterior & $\mathbf{M}$ & 33.92 & 3.66 & 27 & 40 & \multirow{2}{*}{2.46} & \multirow{2}{*}{$\mathrm{S}$} \\
\hline Alveolar and Basal Height & $\mathbf{F}$ & 31.00 & 2.45 & 27 & 35 & & \\
\hline Mandibular Anterior & $\mathbf{M}$ & 10.77 & 2.11 & 8.5 & 15 & \multirow{2}{*}{1.73} & \multirow{2}{*}{ NS } \\
\hline Alveolar Depth & $\mathbf{F}$ & 9.32 & 2.22 & 6.5 & 14 & & \\
\hline Mandibular Anterior & $\mathbf{M}$ & 0.324 & 0.094 & 0.225 & 0.537 & \multirow{2}{*}{0.56} & \multirow{2}{*}{ NS } \\
\hline Alveolar Ratio & $\mathbf{F}$ & 0.304 & 0.089 & 0.191 & 0.509 & & \\
\hline
\end{tabular}

SD: Standard deviation.

* M= Male $(\mathrm{n}=13) ; \mathrm{F}=$ Female $(\mathrm{n}=14)$.

$* *$ Sig.: Significance; NS $=$ Not significant $(p>0.05) ; \mathrm{S}=$ Significant $(p \leq 0.05)$.

$* * *$ All variables were in millimeter except IIA in degrees. 
Table (2): Descriptive and gender's variation analyses of the anterior facial height and its component parameters in deep bite group

\begin{tabular}{|c|c|c|c|c|c|c|c|}
\hline Variables*** & Sex & $\begin{array}{l}\text { Mean } \\
\text { Value }\end{array}$ & \pm SD & $\begin{array}{l}\text { Minimum } \\
\text { Value }\end{array}$ & $\begin{array}{c}\text { Maximum } \\
\text { Value }\end{array}$ & $\begin{array}{c}\mathrm{t}- \\
\text { value }\end{array}$ & Sig.** \\
\hline Lower Anterior & $\mathbf{M}$ & 69.69 & 3.76 & 62 & 77 & \multirow{2}{*}{0.58} & \multirow{2}{*}{ NS } \\
\hline Facial Height & $\mathbf{F}$ & 68.69 & 5.13 & 60 & 76 & & \\
\hline \multirow{2}{*}{ Interincisal Angle } & $\mathbf{M}$ & 130.58 & 7.91 & 118 & 144 & \multirow{2}{*}{-0.05} & \multirow{2}{*}{ NS } \\
\hline & $\mathbf{F}$ & 130.80 & 10.7 & 106.5 & 147 & & \\
\hline \multirow{2}{*}{$\begin{array}{c}\text { Maxillary Anterior } \\
\text { Alveolar and Basal Height }\end{array}$} & $\mathbf{M}$ & 22.42 & 2.67 & 19.5 & 27.5 & \multirow{2}{*}{0.42} & \multirow{2}{*}{ NS } \\
\hline & $\mathbf{F}$ & 22.00 & 2.52 & 17.5 & 25.5 & & \\
\hline \multirow{2}{*}{$\begin{array}{l}\text { Maxillary Anterior } \\
\text { Alveolar Depth }\end{array}$} & $\mathbf{M}$ & 18.46 & 4.41 & 11 & 25.5 & \multirow{2}{*}{0.88} & \multirow{2}{*}{ NS } \\
\hline & $\mathbf{F}$ & 16.69 & 5.78 & 9 & 29 & & \\
\hline \multirow{2}{*}{$\begin{array}{c}\text { Maxillary Anterior } \\
\text { Alveolar Ratio }\end{array}$} & $\mathbf{M}$ & 0.835 & 0.219 & 0.458 & 1.133 & \multirow{2}{*}{0.58} & \multirow{2}{*}{ NS } \\
\hline & $\mathbf{F}$ & 0.776 & 0.298 & 0.391 & 1.277 & & \\
\hline \multirow{2}{*}{$\begin{array}{c}\text { Mandibular Anterior } \\
\text { Alveolar and Basal Height }\end{array}$} & $\mathbf{M}$ & 33.62 & 2.23 & 31 & 38 & \multirow{2}{*}{0.89} & \multirow{2}{*}{ NS } \\
\hline & $\mathbf{F}$ & 32.81 & 2.40 & 29 & 36 & & \\
\hline \multirow{2}{*}{$\begin{array}{l}\text { Mandibular Anterior } \\
\text { Alveolar Depth }\end{array}$} & $\mathbf{M}$ & 11.62 & 2.03 & 7 & 15.5 & \multirow{2}{*}{2.20} & \multirow{2}{*}{$\mathrm{S}$} \\
\hline & $\mathbf{F}$ & 9.77 & 2.23 & 5.5 & 12.5 & & \\
\hline \multirow{2}{*}{$\begin{array}{c}\text { Mandibular Anterior } \\
\text { Alveolar Ratio }\end{array}$} & $\mathbf{M}$ & 0.347 & 0.069 & 0.2000 & 0.484 & \multirow{2}{*}{1.80} & \multirow{2}{*}{ NS } \\
\hline & $\mathbf{F}$ & 0.299 & 0.068 & 0.157 & 0.396 & & \\
\hline
\end{tabular}

SD: Standard deviation; * M= Male ( $\mathrm{n}=13) ; \mathrm{F}=$ Female $(\mathrm{n}=14)$.

** Sig.: Significance; $\mathrm{NS}=$ Not significant $(p>0.05) ; \mathrm{S}=$ Significant $(p \leq 0.05)$.

$* * *$ All variables were in millimeter except interincisal angle in degrees.

Table (3): Descriptive and gender's variation analyses of the anterior facial height and its component parameters in open bite group

\begin{tabular}{|c|c|c|c|c|c|c|c|}
\hline Variables*** & Sex* & $\begin{array}{l}\text { Mean } \\
\text { Value }\end{array}$ & \pm SD & $\begin{array}{l}\text { Minimum } \\
\text { Value }\end{array}$ & $\begin{array}{l}\text { Maximum } \\
\text { Value }\end{array}$ & $\begin{array}{c}\text { t- } \\
\text { value }\end{array}$ & Sig.** \\
\hline \multirow{2}{*}{$\begin{array}{c}\text { Lower Anterior } \\
\text { Facial Height }\end{array}$} & $\mathbf{M}$ & 74.93 & 4.26 & 67.5 & 80 & \multirow{2}{*}{-0.06} & \multirow{2}{*}{ NS } \\
\hline & $\mathbf{F}$ & 75.05 & 5.33 & 66.5 & 82 & & \\
\hline \multirow{2}{*}{ Interincisal Angle } & $\mathbf{M}$ & 114.07 & 7.24 & 102 & 124 & \multirow{2}{*}{-2.52} & \multirow{2}{*}{$\mathrm{S}$} \\
\hline & $\mathbf{F}$ & 123.4 & 11.50 & 104 & 139.5 & & \\
\hline \multirow{2}{*}{$\begin{array}{c}\text { Maxillary Anterior } \\
\text { Alveolar and Basal Height }\end{array}$} & $\mathbf{M}$ & 22.40 & 3.31 & 18.5 & 28.5 & \multirow{2}{*}{0.47} & \multirow{2}{*}{ NS } \\
\hline & $\mathbf{F}$ & 21.86 & 2.04 & 19 & 24.5 & & \\
\hline \multirow{2}{*}{$\begin{array}{l}\text { Maxillary Anterior } \\
\text { Alveolar Depth }\end{array}$} & $\mathbf{M}$ & 16.10 & 4.15 & 9.5 & 25.5 & \multirow{2}{*}{1.66} & \multirow[b]{2}{*}{ NS } \\
\hline & $\mathbf{F}$ & 13.50 & 3.61 & 10 & 23 & & \\
\hline \multirow{2}{*}{$\begin{array}{l}\text { Maxillary Anterior } \\
\text { Alveolar Ratio }\end{array}$} & $\mathbf{M}$ & 0.732 & 0.213 & 0.440 & 1.159 & \multirow{2}{*}{1.48} & \multirow{2}{*}{ NS } \\
\hline & F & 0.620 & 0.156 & 0.416 & 0.978 & & \\
\hline \multirow{2}{*}{$\begin{array}{c}\text { Mandibular Anterior } \\
\text { Alveolar and Basal Height }\end{array}$} & $\mathbf{M}$ & 34.20 & 2.26 & 30 & 37 & \multirow{2}{*}{0.02} & \multirow{2}{*}{ NS } \\
\hline & $\mathbf{F}$ & 34.18 & 2.19 & 30.5 & 37 & & \\
\hline \multirow{2}{*}{$\begin{array}{l}\text { Mandibular Anterior } \\
\text { Alveolar Depth }\end{array}$} & $\mathbf{M}$ & 9.83 & 1.44 & 6.5 & 12 & \multirow{2}{*}{1.07} & \multirow{2}{*}{ NS } \\
\hline & $\mathbf{F}$ & 9.05 & 2.31 & 4 & 13 & & \\
\hline \multirow{2}{*}{$\begin{array}{l}\text { Mandibular Anterior } \\
\text { Alveolar Ratio }\end{array}$} & $\mathbf{M}$ & 0.290 & 0.054 & 0.180 & 0.366 & \multirow{2}{*}{1.00} & \multirow{2}{*}{ NS } \\
\hline & $\mathbf{F}$ & 0.265 & 0.069 & 0.111 & 0.393 & & \\
\hline
\end{tabular}

SD: Standard deviation, * M= Male ( $\mathrm{n}=13) ; \mathrm{F}=$ Female $(\mathrm{n}=14)$.

** Sig.: Significance; NS= Not significant $(p>0.05)$; $\mathrm{S}=$ Significant $(p \leq 0.05)$.

$* * *$ All variables were in millimeter except interincisal angle in degrees.

The genders variation (ANOVA and Duncan's analyses) for the LAFH and its component parameters were appeared that the normal over bite group was significantly increase mean value $(p \leq 0.05)$ in male than female in the MxAAD, MxAAR and
MdAABH parameters. The open bite group demonstrated significantly higher mean value $(p \leq 0.05)$ in female than male in the IIA parameter only. The deep bite groups showed significantly greater mean value $(p$ $\leq 0.05)$ in male than female in the MdA- 
AD parameter only.

The over bite groups variation (ANOVA and Duncan analyses) for the mean value (total male and female mean value) of the LAFH and its component parameters at $p \leq 0.05$ significant level presented in Table (4) and Figure (2) and (3). All the parameters displayed no significant difference $(p>0.05)$ except that the open bite group which disclosed significantly greater mean value $(p \leq 0.05)$ in the LAFH, and it was significantly lower mean value $(p \leq$ $0.05)$ in the IIA angle when compared with normal and deep bite groups.

Table (4): Multiple range variation of the LAFH and its component parameters among the three type of over bite

\begin{tabular}{|c|c|c|c|c|c|c|}
\hline \multirow{2}{*}{ Variables* } & \multicolumn{2}{|c|}{$\begin{array}{c}\begin{array}{c}\text { Normal Bite Group } \\
\mathbf{n}=27\end{array} \\
\end{array}$} & \multicolumn{2}{|c|}{$\begin{array}{c}\text { Deep Bite Group } \\
n=26\end{array}$} & \multicolumn{2}{|c|}{$\begin{array}{c}\text { Open Bite Group } \\
n=26\end{array}$} \\
\hline & Mean & $\pm \mathrm{SD}$ & Mean & $\pm \mathrm{SD}$ & Mean & $\pm S D$ \\
\hline $\begin{array}{l}\text { Lower Anterior } \\
\text { Facial Height }\end{array}$ & $70.556^{\mathrm{a}}$ & 4.192 & $69.102^{\mathrm{a}}$ & 4.434 & $74.981^{b}$ & 4.640 \\
\hline Interincisal Angle & $125.13^{b}$ & 8.86 & $130.67^{b}$ & 9.19 & $118.00^{\mathrm{a}}$ & 10.23 \\
\hline $\begin{array}{c}\text { Maxillary Anterior } \\
\text { Alveolar and Basal Height }\end{array}$ & $21.074^{\mathrm{a}}$ & 1.702 & $22.212^{\mathrm{a}}$ & 2.554 & $22.173^{\mathrm{a}}$ & 2.807 \\
\hline $\begin{array}{l}\text { Maxillary Anterior } \\
\text { Alveolar Depth }\end{array}$ & $15.722^{a}$ & 5.276 & $17.577^{\mathrm{a}}$ & 5.118 & $15.000^{\mathrm{a}}$ & 4.072 \\
\hline $\begin{array}{l}\text { Maxillary Anterior } \\
\text { Alveolar Ratio }\end{array}$ & $0.314^{\mathrm{a}}$ & 0.090 & $0.323^{\mathrm{a}}$ & 0.072 & $0.279^{\mathrm{a}}$ & 0.061 \\
\hline $\begin{array}{c}\text { Mandibular Anterior } \\
\text { Alveolar and Basal Height }\end{array}$ & $32.407^{\mathrm{a}}$ & 3.374 & $33.212^{\mathrm{a}}$ & 2.307 & $34.192^{\mathrm{a}}$ & 2.187 \\
\hline $\begin{array}{l}\text { Mandibular Anterior } \\
\text { Alveolar Depth }\end{array}$ & $10.019^{\mathrm{a}}$ & 2.251 & $10.692^{\mathrm{a}}$ & 2.294 & $9.500^{\mathrm{a}}$ & 1.855 \\
\hline $\begin{array}{l}\text { Mandibular Anterior } \\
\text { Alveolar Ratio }\end{array}$ & $0.746^{\mathrm{a}}$ & 0.236 & $0.805^{\mathrm{a}}$ & 0.258 & $0.684^{\mathrm{a}}$ & 0.195 \\
\hline
\end{tabular}

Different letters mean significant difference at 0.05 level.

Same letters mean no significant difference at 0.05 level.

*All variables were in millimeter except interincisal angle in degrees.

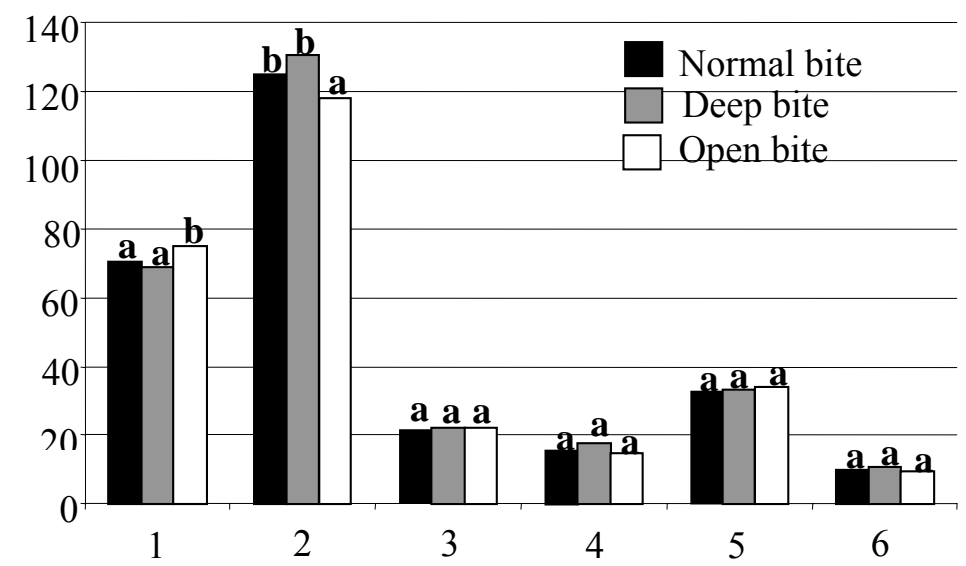

Figure (2): The differences in the values of the LAFH's component parameters among the three type of over bite

1: Lower anterior facial height; 2: nterincisal angle; 3: Maxillary anterior alveolar and basal height; 4: Maxillary anterior alveolar depth; 5: Mandibular anterior alveolar and basal height; 6: Mandibular anterior alveolar depth

All variables were in millimeter except (IIA) in degree.

Different letters mean significant difference at 0.05 level.

Same letters mean no significant difference at 0.05 level. 


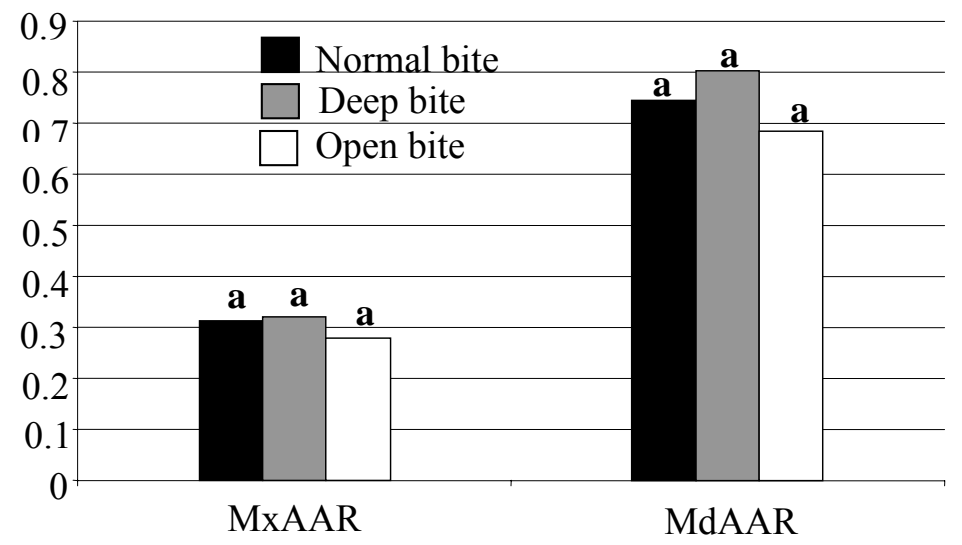

Figure (3): The differences in the values of the LAFH's component parameters among the three type of over bite

MxAAR: Maxillary anterior alveolar ratio; MdAAR: Mandibular anterior alveolar ratio. All variables were in millimeter.

Same letters mean no significant difference at 0.05 level.

\section{DISCUSSION}

The insignificant gender's variation of all parameters except MxAAD, MxA$\mathrm{AR}$ and MdAABH in normal over bite group, as well as, in open bite group except IIA and in deep bite group except MdAAD indicated that these parameters were more stable in Class I dentoskeletal relationship and were not affected by the gender. This could be due to that parameters are strongly related to the same dentoalveolar and skeletal growth pattern of Class I dentoskeletal relationship. The insignificant gender's variation coincided with findings of the Beckermann et al., ${ }^{(20)}$ who reported the general pattern of differences of these parameters were gender independent. Other studies in normal over bite group demonstrated no gender variation in IIA, ${ }^{(21-23)}$ whereas others reported no genders variation in LAFH. ${ }^{(21,24,25)}$ Contradictory studies were found significant gender variation in the $\mathrm{LAFH}^{(24-27)}$ and in IIA. ${ }^{(24)}$

The significant gender variation in the MxAAD, MxAAR and MdAABH were appeared in the normal over bite. This disclose the property of normal over bite is relatively associated with greater mean value of these parameters in male than female, whereas the deep bite group showed significantly increase mean value in male than female in the MdAAD parameter, and the open bite revealed significantly increase mean value in male than female in IIA parameters. These variations could be due to compensatory growth changes in the de- ntoalveolar components to approach the normal over bite relationship which was appeared more in male than female. This conclusion coincided with suggestion of other studies, ${ }^{(28,29)}$ which reported that the alveolar structure plays role in establishing the vertical maxillomandibular relationships. Ismail and $\operatorname{Barcin}^{(29)}$ reported that the MxAABH parameter was significantly gender variation in the over bite groups, whereas Beckermann et al. ${ }^{(28)}$ did not find significant gender variation in the LAFH component parameters in over bite groups.

The over bite groups variation of the LAFH and its component parameters demonstrated that the open bite group was significantly increase of mean value at $p \leq$ 0.05 in the LAFH and significantly decrease at $p \leq 0.05$ in IIA than the other over bite groups. This result obviously due to that open bite subject has increase in the LAFH and could change the incisor teeth inclination (decreasing the IIA). These results were confirmed with that of Beckermann et al., ${ }^{(20,28)}$ who reported that the LAFH had large correlation with over bite groups. Other studies ${ }^{(30-32)}$ disclosed that the open bite group characterized by long LAFH than deep bite group. Beckermann et al. ${ }^{(28)}$ reported that the upper incisor was generally protruded in open bite group than normal over bite group, whereas in deep bite group the maxillary incisors was generally more inclined than normal over bite group. Meanwhile, the open bite group appeared insignificant mean value at $p>0.05$ in 
MxAABH, MxAAD, MxAAR, MdAABH, MdAAD and MdAAR when compared with the normal and deep bite groups. These results indicated that the compensatory growth of the alveolar structures of the LAFH was not statically affected by the changing the overbite. These findings were coincided with that of Beckermann et al. ${ }^{(28)}$ regarding MxAAD, MdAAR. Other studies ${ }^{(33-35)}$ reported no significant differences in the anterior dentoalveolar height among the overbite groups, whereas Richardson $^{(36)}$ reported no abnormalities in anterior alveolar height between open bite and deep bite groups. The results were contradictory to the findings of Beckermann et $a l .{ }^{(28)}$ regarding the $\mathrm{MxAABH}, \mathrm{MdAABH}$, MdAAD and MxAAR. Other studies ${ }^{(37-39)}$ reported that the anterior dentoalveolar height was significantly greater in open bite group when compared with deep bite group in maxilla only.

The deep bite group disclosed no significant differences at $p>0.05$ in the LA$\mathrm{FH}$ and its component parameters (LAFH, IIA, MxAABH, MxAAD, MxAAR, MdAABH, MdAAD and MdAAR) when compared with normal over bite group. This clearly indicated that the dentoskeletal structures of the lower facial height in deep bite patients were not statically influenced by the decreasing of the vertical incisal relation. These results came in accordance with that of Beckermann et al. ${ }^{(28)}$ regarding $\mathrm{Mx}$ AAD and MdAAR. Contrast findings have been demonstrated by some researchers. Beckermann et al. ${ }^{(28)}$ revealed significant differences regarding the LAFH, IIA, MxAABH, MxAAR, MdAABH and MdA$A D$. Ismail and Barcin ${ }^{(29)}$ found significant difference among the over bite groups concerning the MxAABH, MxAAR, MdAA$\mathrm{BH}$ and the dentoalveolar height of the maxilla and mandible.

\section{CONCLUSIONS}

The conclusions of this study can be derived in that the significant gender variation of the LAFH and its components of the normal over bite group were appeared in MxAAD, MxAAR and mandibular anterior alveolar height. Whereas in deep bite group appeared in MdAAD, and in open bite group demonstrated in the IIA. The si- gnificant variation of the LAFH and its components among the over bite groups were disclosed that the LAFH was significantly increase in open bite than the normal and deep bite groups. The IIA was shown significantly decrease in open bite group than the normal and deep bites groups.

\section{REFERENCES}

1. Wylie WL. The assessment of antroposterior dysplasia. Angle Orthod. 1947; 17: 97-109.

2. Bjork A. Cranial base development. Am J Orthod. 1955; 41: 198-225.

3. Canonn J. Craniofacial height and depth increments in normal children. Angle Orthod. 1970; 40: 202-218.

4. Proffit WR, Field HW, Ackerman JL, Sinclair PM, Thomas PM, Tulloch JFC. Contemporary Orthodontics. $3^{\text {rd }}$ ed. Mosby Yearbook, Inc. 2000; p: 189.

5. Graber TM. Orthodontics: Principles and Practice. $3^{\text {rd }}$ ed. WB Saunders Co. Philadelphia. 1972; Pp: 51, 57, 65, 76.

6. Adams CP, Kerr WJS. Over bite and face height in 44 male subjects with Class I, Class II/ 1 and Class II/2 occlusion. Eur J Orthod. 1981; 3: 125-129.

7. Dung DJ, Smith RJ. Cephalometric and clinical diagnosis of open bite tendency. Am J Orthod Dentofac Orthop. 1988; 94 : 486-492.

8. Fleming HB. An investigation of the vertical over bite during the eruption of the permanent dentition. Angle Orthod. 1961; 31: 53-62.

9. Reiolo ML, Moyers RE, McNamara JA, Hunter WS. An Atlas of Craniofacial Growth Cephalometric Standards. Monograph 2 Craniofacial Growth Series. Ann Arbor Center for Human Growth and Development. University of Michigan. 1974; Pp: 14-20.

10. Kim YH. Over bite depth indicator with particular reference to anterior open bite. Am J Orthod. 1974; 65: 485-492.

11. Prakash P, Margolis H. Dento-craniofacial relations in varying degree of over bites. Am J Orthod. 1952; 38: 657-673.

12. Hapak FN. Cephalometric appraisal of the open bite case. Angle Orthod. 1964; 34: 114-127.

13. Kinann BK. Over jet and over bite distribution and correlation: A comparative 
epidemiological English-Iraqi study. $\mathrm{Br}$ J Orthod. 1986; 12: 79-86.

14. Steiner CC. Cephalometric for you and me. Am J Orthod. 1953; 39: 729-754.

15. Steiner CC. The use of cephalometric as an aid to planning and assessing orthodontic treatment. Am J Orthod. 1961; 47: 721-748.

16. Bjork A. The significance of growth changes in facial pattern and relationship to changes in occlusion. Dent Rec. 1951; 71: 197-212.

17. Downs WB. Variations if facial relationships, their significance in treatment and prognosis. Am J Orthod. 1948; 34: 812840.

18. Downs WB. Analysis of dentofacial profile. Angle Orthod. 1956; 26: 191-212.

19. Steiner CC. Cephalometrics in clinical practice. Angle Orthod. 1959; 29: 8-29.

20. Beckermann SH, Kuitert RB, Prahl-Andersen B, Segner D, Tuinzing DB. Alveolar and skeletal dimensions associated with lower face height. Am J Orthod Dentofac Orthop. 1998; 113: 498-506.

21. Al-Sayagh NM. Dentoskeletal analysis and facial types of Iraqi adults in Mosul City with Class I normal occlusion (A lateral radiographic cephalometric study). MSc thesis. College of Dentistry. University of Mosul. 1999.

22. Miyajlma K, McNamara JA, Kimura T, Murata S, Luzika T. Craniofacial structure of Japanese and European American adults with normal occlusion. Am J Orthod Dentofac Orthop. 1996; 110: 431438.

23. El-Faituri H. Cephatometric norms for Libyan population. Arab Dent J. 1994; 1: 35-46.

24. Adam AI. Skeletal norms for Sudanese adults with Class I normal occlusion (Lateral cephalometric study). MSc thesis. College of Dentistry. University of Mosul. 2001.

25. Park I, Bowman D, Klapper L. A cephalometric study of Korean adults. Am J Orthod Dentofac Orthop. 1989; 96: 54-59.

26. Al-Katifi BSh. Prosthodontic cephalometric standards and their relation to facial type in Iraqi adult sample (Radiographic cephalometric study). MSc thesis. College of Dentistry. University of Baghdad. 1994.
27. Gasgoos SS. Three dimensional analysis of nasomaxillary complex of Iraqi adults (18-25 years) in Mosul City with Class I normal occlusion (Radiographic cephalometric study). MSc thesis. College of Dentistry. University of Mosul. 2000.

28. Beckermann SH, Kuitert RB, Prahl-Andersen B, Segner D, Tuinzing DB. Alveolar and skeletal dimension associated with over bite. Am J Orthod Dentofac Orthop. 1998; 113: 443-452.

29. Ismail C, Barcin UEr. The effects of over bite on the maxillary and mandibular morphology. Angle Orthod. 2000; 70: 110-115.

30. Subtenly JD, Sakuda M. Open bite diagnosis and treatment. Am J Orthod. 1964; 50: 337-358.

31. Sassouni V, Nanda S. Analysis of dentofacial vertical proportions. Am J Orthod. 1964; 50: 801-823.

32. Richardson A. Skeletal factors in anterior open bite and deep bite. Am J Orthod. 1969; 56: 114-127.

33. Weinback JR. Cephalometric changes during treatment with open bite bionator. Am J Orthod Dentofac Orthop. 1992; 101: 367-374.

34. Nahoum HI, Horowitz SL, Benedicto EA. Varieties open bite. Am J Orthod. 1971; 60: 486-492.

35. Lowe AA. Correlations between orofacial muscle activity and craniofacial morphology in a sample of control and anterior open bite subjects. Am J Orthod. 1980; 78: 89-97.

36. Richardson A. Dentoalveolar factors in anterior open bite and deep bite. Dent Prac Dent Rec. 1970; 21: 53-57.

37. Lopez-Gavito G, Wallen TR, Little RM, Joondeph DR. Anterior open bite malocclusion: A longitudinal 10 years post retention evaluation of orthodontically treated patients. Am J Orthod. 1985; 87: 175186.

38. Ellis E, McNamara JA. Components of adults Class II malocclusion. Am J Orthod. 1984; 86: 277-290.

39. Frost DE, Fonesca RJ, Turvey TA, Hall DJ. Cephalometric diagnosis of a pertogentia. Am J Orthod. 1980; 78: 657-699. 